\title{
Kindergarten Student's Approaches to Resolving Open-Ended Design Tasks
}

\author{
Scott R. Bartholomew, Cameron Moon, Emily Yoshikawa Ruesch, \\ \& Greg J. Strimel
}

\begin{abstract}
Research on children's experiences with designing has emphasized cognitive processes, self-efficacy, and outcomes related to designing. However, efforts have been limited towards identifying approaches children use while designing and making decisions related to design. This study, which incorporated a qualitative analysis of children's design portfolios, explored students' decisions in planning and evaluating designs related to children's nursery rhymes. Differences in design approaches, based on teacher, task, and stage of designing, were identified in the analysis. Understanding how children approach and attempt to solve open-ended design problems may assist in improving student design experiences and pedagogical practices in all levels of education.
\end{abstract}

Keywords: Decision making, Design-based learning, integrated STEM education, kindergarten, open-ended design, primary school

The emphasis on science, technology, engineering, and mathematics (STEM) education in recent years represents a movement towards preparing students for societal contribution in an increasingly technologically advanced world (International Technology Education Association, 2007; National Research Council [NRC], 2012). Those in favor of an increased emphasis on STEM and integrated STEM education cite benefits such as increased abilities in problem solving (Stohlmann, Moore, \& Roehrig, 2012), teamwork, collaboration (Savery, 2015), innovation, and creativity (Morrison, 2006). Efforts in broadening STEM participation and education have spanned all grade levels (Honey \& Kanter, 2013) and have traditionally been linked with increased preparation of future workforce talent. Overall, the calls for STEM education and workforce preparation have largely emphasized the need for students to be better prepared in navigating open-ended scenarios within design contexts that often require teamwork, creativity, and innovation (Griffin \& Care, 2015).

Preparing students for success in open-ended design problems has led to new approaches to education, assessment, and pedagogy (NRC, 2011). Efforts toward understanding how students engage in and with these types of problems have been promising, with key findings related to design cognition (Grubbs, Strimel, \& Kim, 2018; Strimel, Bartholomew, Kim \& Zhang, 2018) and other 
student factors (Bartholomew \& Strimel, 2018) being highlighted in relation to student capacity with open-ended problem success.

\section{Statement of the Problem}

Despite the documented research around STEM education, design, and open-ended problem solving, limited research has investigated the approaches taken by primary school students, specifically those in Kindergarten, when solving open-ended design tasks. Most of the research related to primary school students in STEM education revolves around the benefits of STEM participation for student motivation, self-efficacy, and career interest. However, although some research has emphasized the breadth and depth of cognitive strategies employed by students when engaged in design (Kelley \& Sung, 2017; Kelley, Capobianco, \& Kaluf, 2015; Strimel, Kim, Bartholomew, \& Cantu, 2018), limited examinations of the actual approaches taken by primary school students while solving these types of problems have been presented. Addressing this research gap can be of specific importance because design activities have now become pervasive in elementary school coursework through programs such as Engineering is Elementary, Project Lead the Way Launch, and Engineering byDesign. Although there are some theories about cognitive development indicating that young students may be unable to operate in an open-ended design space (e.g., Piaget's Theory of Cognitive Development), others have pointed out how such a theory can underestimate the development of children because their learning capabilities and biological maturation can vary widely when compared to others their age (e.g., Cohen, 2002; Crossland, 2015; Weiten, 1992). Sutherland (1992) specifically pointed out that Piaget acknowledged this possibility in his later work, which emphasized creating the most appropriate learning environments for children. Considering these cognitive development discussions, we believe that an understanding of how Kindergarteners (ages 56) approach and attempt to solve open-ended design problems may shed light on primary school student design decision making and assist in identifying potentially useful pedagogical approaches for improving student achievement in these areas through the scaffolding of design activities and implementation of hierarchical design practices.

\section{Research Questions}

Recognizing the emphasis on STEM education and open-ended problem solving for students of all ages and the findings related to cognitive strategies, we determined to investigate how students approach open-ended design tasks. Specifically, we investigated primary school children in Kindergarten with the following research question framing this investigation: What approaches do Kindergarten students use when making decisions in the process of resolving open-ended design tasks within integrated STEM learning contexts? 


\section{Integrated STEM Learning in Primary Schools}

With a global emphasis on STEM education, school systems have made increasing efforts to implement integrated pedagogical approaches centered on problem-based or design-based learning into their curriculum (Honey, Pearson, \& Schweingruber, 2014). STEM integration has not only reached secondary education but has been implemented in primary education as well (Rich, Jones, Belikov, Yoshikawa, \& Perkins, 2017). Various findings have emerged from these efforts, including increased self-efficacy (Marra, Rodgers, Shen \& Bogue, 2009), increased likelihood of majoring in STEM-related fields (Katehi, Pearson, \& Feder, 2009), increases in student autonomy (León, Núñez, \& Liew, 2015), and earlier student involvement in STEM coursework (Tyler-Wood, Knezek, \& Christensen, 2010; Stohlmann et al., 2012).

Despite these preliminary findings, concerns around the preparation of the educator workforce have been raised (Rich et al., 2017). Currently, the educators working with primary-aged students are often not required to teach integrated STEM nor are they required to obtain an endorsement or any formal education in integrated STEM learning prior to receiving a license (Epstein \& Miller, 2011). Research has shown that these educators can be unmotivated to receive STEM training because all areas of STEM do not have equally high standards (Brophy, Klein, Portsmore, \& Rogers, 2008). Further, for those educators who do receive STEM training, there often remains a lack of technical background in science, engineering, and technology (Swift \& Watkins, 2004). However, notwithstanding these challenges, implementation of STEM education may be feasible and successful at lower grade levels, such as Kindergarten (ages 5-6), because these activities may foster excitement, creativity, and engagement in students (Cunningham \& Lachapelle, 2007).

\section{Open-Ended Design and Design Portfolios}

One commonly used approach to integrated STEM learning is immersing students in open-ended problems that often involve some element of design (Diefes-Dux, Moore, Zawojewski, Imbrie, \& Follman, 2004). These experiences provide students with a design scenario and the accompanying criteria and constraints to guide them as they seek to develop a resolution to an open-ended problem. This type of design-based teaching has been linked with improvement of teacher self-efficacy and learning for elementary school students (Bencze, 2010). However, other evidence may suggest that open-ended design experiences can divert students from recognizing and developing an understanding of the desired concepts of the learning situation, thus reducing their ability to transfer knowledge to other situations (Goldstone \& Sakamoto, 2003; Honey et al., 2014; Sloutsky, Kaminski, \& Heckler, 2005).

Related to open-ended design problems are design portfolios, which often serve as a means for recording student progress and experiences while designing (Johnson, Mims-Cox, \& Doyle-Nichols, 2010). Efforts to track student progress, 
thinking, and designing while engaged in these problems have also included a variety of media similar to portfolios, such as journals and worksheets (Schallhart \& Wieden-Bischof, 2010; Arter \& Spandel, 1992). Design portfolios have been implemented across all levels of education (Arter \& Spandel, 1992) and have been shown to be successful at a primary level in various activities and environments (Hall \& Hewitt-Gervais, 2000). As students work with design portfolios, they may build upon previous knowledge, deepen their understanding of class material, and increase in self-reflection (Jacobs, 2001; Zubizarreta, 2009). Portfolios have also been linked with increases in technical skills, critical thinking, writing, and problem solving (De Fina, 1992; Koch \& Burghardt, 2002; Nicolaidou, 2013).

\section{Approaches to Solving Open-Ended Design Problems}

Jonassen (2008) broadly describes the approach of design as an iterative process of decision-making with each decision iteration helping to reduce the complexities toward achieving a design resolution. More recently, because design has become prevalent in STEM education initiatives, a wide range of design process models and approaches have been developed and implemented in classroom learning environments (Strimel \& Grubbs, 2017). However, research efforts focused on determining the actual approaches students take when solving design problems and the merit of such approaches are limited (Dixon, 2016). Instead, most of the research related to open-ended design involves the use of think-aloud protocols and cognitive strategy identification (Pringle \& Sowden, 2017). For example, Kelley, Capobianco, and Kaluf (2015) used think-aloud protocols with primary-aged students and found that the students were able to define the problem, identify criteria and constraints, and generate multiple ideas. Relatedly, Strimel, Bartholomew, Kim, and Zhang (2018) found that the majority of primary-aged students' time in designing was connected to manipulating materials, and limited time was spent defining the problem or applying design criteria. Resnick (1998) found that primary students typically focus on manipulating physical objects while working on open-ended problems.

In related research, outside of think-aloud protocols, Fleer (2000) worked with primary-aged children engaged in designing and used a linear process for design with three steps: planning, making, and evaluating. Fleer explained that planning involves brainstorming by writing or drawing out ideas, making involves creating the design using various materials, and evaluating involves reflecting on the design and determining what could be done to improve.

\section{Methods}

We sought to build on Fleer's (2000) research by specifically investigating the approaches students used while designing. We chose to emphasize the planning (Stage 1) and evaluating (Stage 3) periods of design, as defined by Fleer. These stages represented readily identifiable starting and stopping points 
for the chosen design tasks because the provided portfolios (see Figure 1 for an example) specifically prompted the students in making decisions related to their designs at these stages of their design process. Although the inclusion of an analysis around the making stage (Stage 2) of design would have been ideal, limitations related to time and the large sample size $(N=55)$ precluded efforts in this area.

Fleer's (2000) linear process of design was used for this study because the design activities were constrained by classroom schedules and students completing sections of their portfolios following a prescribed classroom implementation timeline. Although potentially limiting, cooperation by the classroom teachers and schools required the adherence to the timeline and portfolio.

Because our intended research sample involved young students, we elected to collect and analyze student drawings and the accompanying explanations that were created during several open-ended design challenges. Our research process involved: (a) the creation of open-ended design activities, (b) the implementation of these design activities with primary-aged students, and (c) the collection and analysis of student design portfolios to investigate our identified research question. Three teachers were recruited for participation in the study. Two of the teachers taught at one school, and the third taught at a different school. The participating teachers all taught Kindergarten students (ages 5-6) in a Midwestern state in the United States. Demographics were similar in all three classrooms, including student's socioeconomic status (22-35\% free and reduced-price lunch) and teacher background with integrated STEM teaching and open-ended design problems (limited experience). All students enrolled in these teachers' classes were recruited for participation in the study based on their teachers' participation.

Primary School Children Design Problems. In an effort to provide the students with design problems that were relevant and engaging, the researchers reviewed available resources for primary school-aged children related to STEM and open-ended design and discussed the curriculum with the participating teachers. After reviewing a variety of resources, the researchers determined to create several open-ended design challenges centered on popular children's rhymes that were scheduled to be covered in the participating class' curriculum (see Table 1). 
Table 1

Nursery Rhyme Design Challenges and Criteria and Constraints

\begin{tabular}{|c|c|c|}
\hline Nursery Rhyme & Challenge & Criteria and Constraints \\
\hline $\begin{array}{l}\text { Baa Baa Black } \\
\text { Sheep (Yoshikawa } \\
\text { \& Bartholomew, } \\
\text { 2017) }\end{array}$ & $\begin{array}{l}\text { Design a way for the } \\
\text { black sheep and its } \\
\text { master to separate the } \\
\text { wool into three bags. }\end{array}$ & $\begin{array}{l}\text { Creates three equal piles } \\
\text { of the "wool." }\end{array}$ \\
\hline $\begin{array}{l}\text { Itsy Bitsy Spider } \\
\text { (Yoshikawa \& } \\
\text { Bartholomew, } \\
\text { 2018a) }\end{array}$ & $\begin{array}{l}\text { Design a way to stop the } \\
\text { spider from climbing the } \\
\text { water spout. }\end{array}$ & $\begin{array}{l}\text { Water still needs to be } \\
\text { able to come out of the } \\
\text { spout while restricting } \\
\text { access for the spider. }\end{array}$ \\
\hline $\begin{array}{l}\text { Little Boy Blue } \\
\text { (Yoshikawa \& } \\
\text { Bartholomew, } \\
\text { 2018b) }\end{array}$ & $\begin{array}{l}\text { Design a way to wake up } \\
\text { Little Boy Blue when the } \\
\text { sheep or cattle are } \\
\text { wandering. }\end{array}$ & $\begin{array}{l}\text { No power source is } \\
\text { available-design must } \\
\text { wake up Little Boy Blue. }\end{array}$ \\
\hline
\end{tabular}

The researchers first identified a clear problem in each of the chosen children's rhymes (i.e., how can we keep the spider from climbing up the water spout) and then used the problems to frame the criteria and constraints and produce a design portfolio for students to use while designing (see Figure 1). 


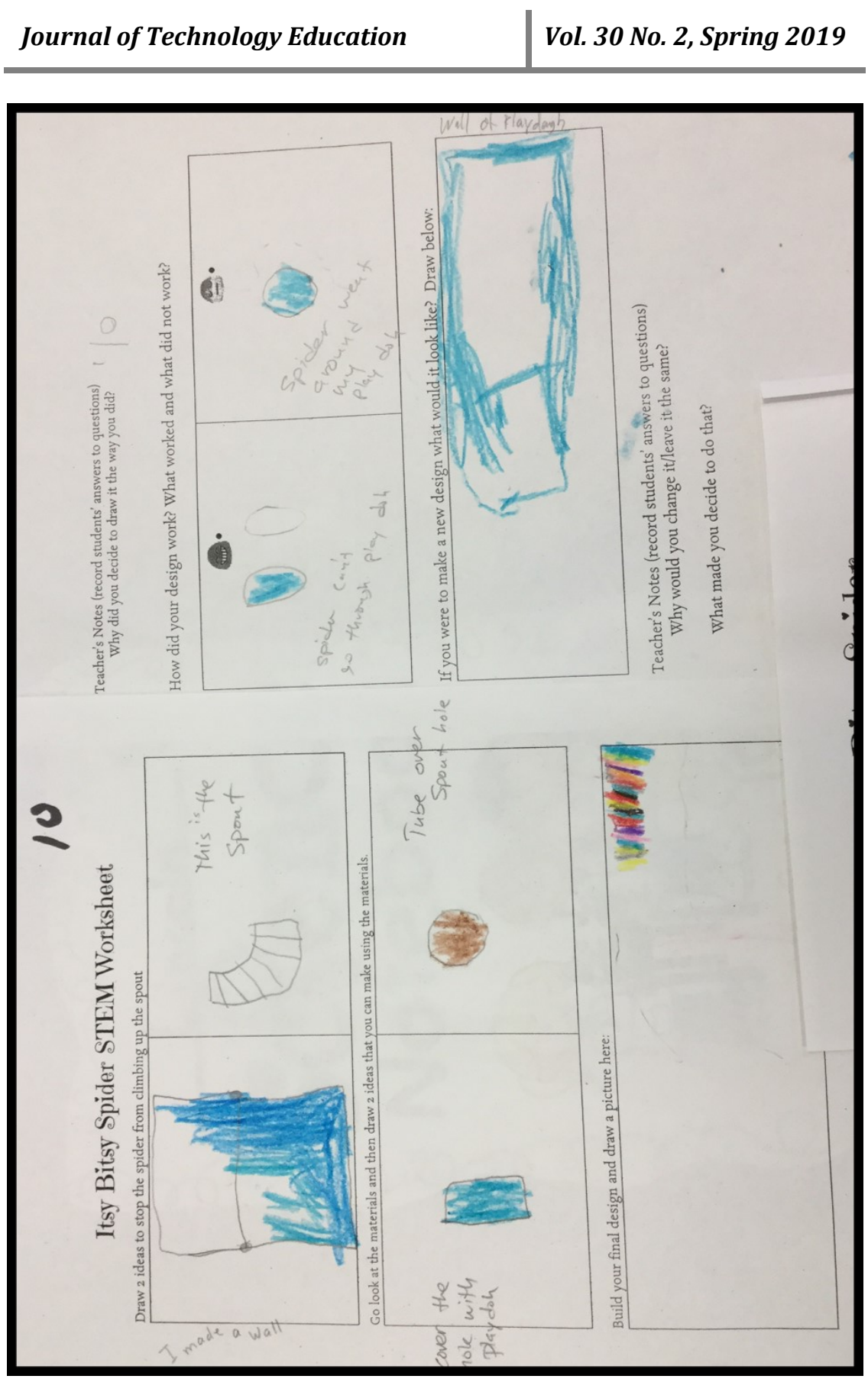

Figure 1. Example of a design portfolio for the Itsy Bitsy Spider task. 
The children's rhymes, and associated design tasks, were field-tested with a primary school-aged student in one of the classes to identify any potential revisions necessary to address activity appropriateness. This student engaged in each of the problems while a researcher observed and identified areas needing clarification, adjustment, and direction. Design challenges and portfolios were adjusted following this field-testing and readied for further research. After meeting with the participating teachers, the design portfolio worksheets for each problem were provided to the teachers. Additionally, a variety of items were collected by the teachers for student use in prototyping potential solutions to the design problems. These items were collected from students and included readily available materials such as plastic, paper, cardboard, tape, and glue.

\section{Implementation and Data Collection}

Prior to the first design problem, the researchers visited the three classes, explained the research study, and disseminated permission forms. Researchers returned to the classes, retrieved permission forms, and scheduled time with the students $(N=55)$ and teachers for a 3-week span to introduce each of the three design tasks (one per week). Each design task took approximately 1 hour of class time and was completed individually by the students. During the design task, the researchers followed a script to introduce the problem, guide students through the design portfolio creation, facilitate the prototype creation by students, and take pictures of the student design portfolios and prototypes.

Prior to each lesson, the participating teachers familiarized their students with the associated children's rhyme and disseminated permission forms for participation. During the lesson, a member of the research team recited the rhyme with the students and discussed the design problem included in the rhyme. Students were then given a design portfolio and led through the process of solving the problem and filling out their portfolio by a member of the research team.

Each design portfolio worksheet (see Figure 1) was designed to guide students through different stages of design (e.g., planning, making, and evaluating), and at each step of the process, students were prompted to draw a picture of their ideas, challenges, and successes - this was important because none of these students (ages 5-6) knew how to read or write. Following each opportunity to draw, the students were prompted by a member of the research team to explain their drawings. Because students of this age lack some communication skills (both verbal and graphic), members of the research team asked follow-up questions to students until an understanding of students' intent was reached. This was then recorded by a member of the research team on the portfolios for later analysis (see Figure 2). 


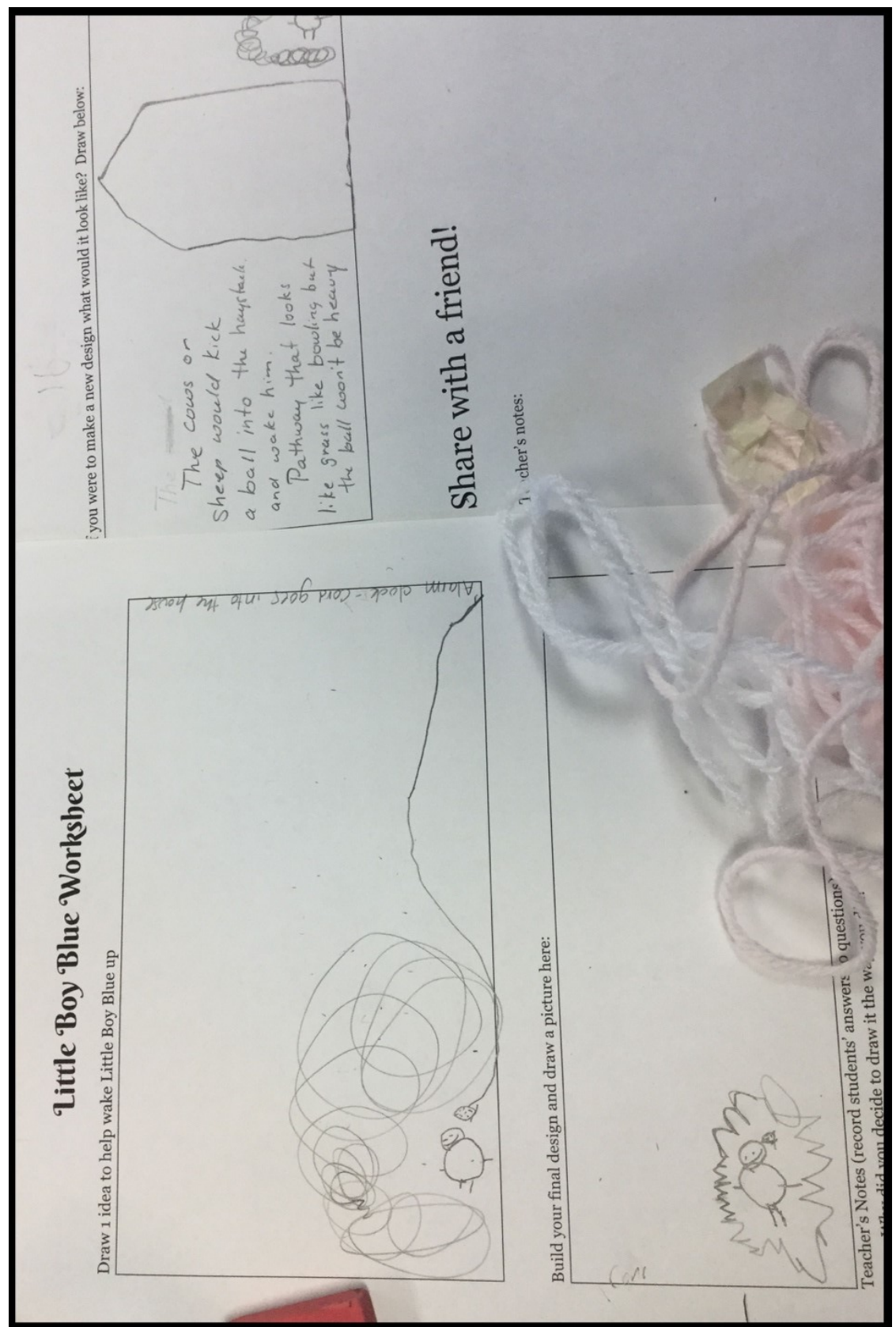

Figure 2. Example of a completed design portfolio and the research notes made throughout the design process.

$-98-$ 
Students were initially asked to brainstorm and draw ideas to help them solve the problem connected with the nursery rhyme. After the initial brainstorming (e.g., Planning phase, see Figure 2), drawing, and notes by the researcher, students were given access to the low-fidelity prototyping supplies and were asked to once again draw what might help them solve the problem-this time focusing on the materials provided. After drawing an idea and explaining their idea to a member of the research team, the students were given access to the supplies and allowed time to create and test their solution prototype (see Figure 3 ). Following the making and testing stage, the students were invited a third time to draw how they would solve the problem if they were to begin again (e.g., evaluation stage; see Figure 4). As before, these drawings were explained to a member of the research team who recorded the student thoughts on their portfolio. 


\begin{tabular}{|l|l|} 
Journal of Technology Education & Vol. 30 No. 2, Spring 2019 \\
\hline
\end{tabular}

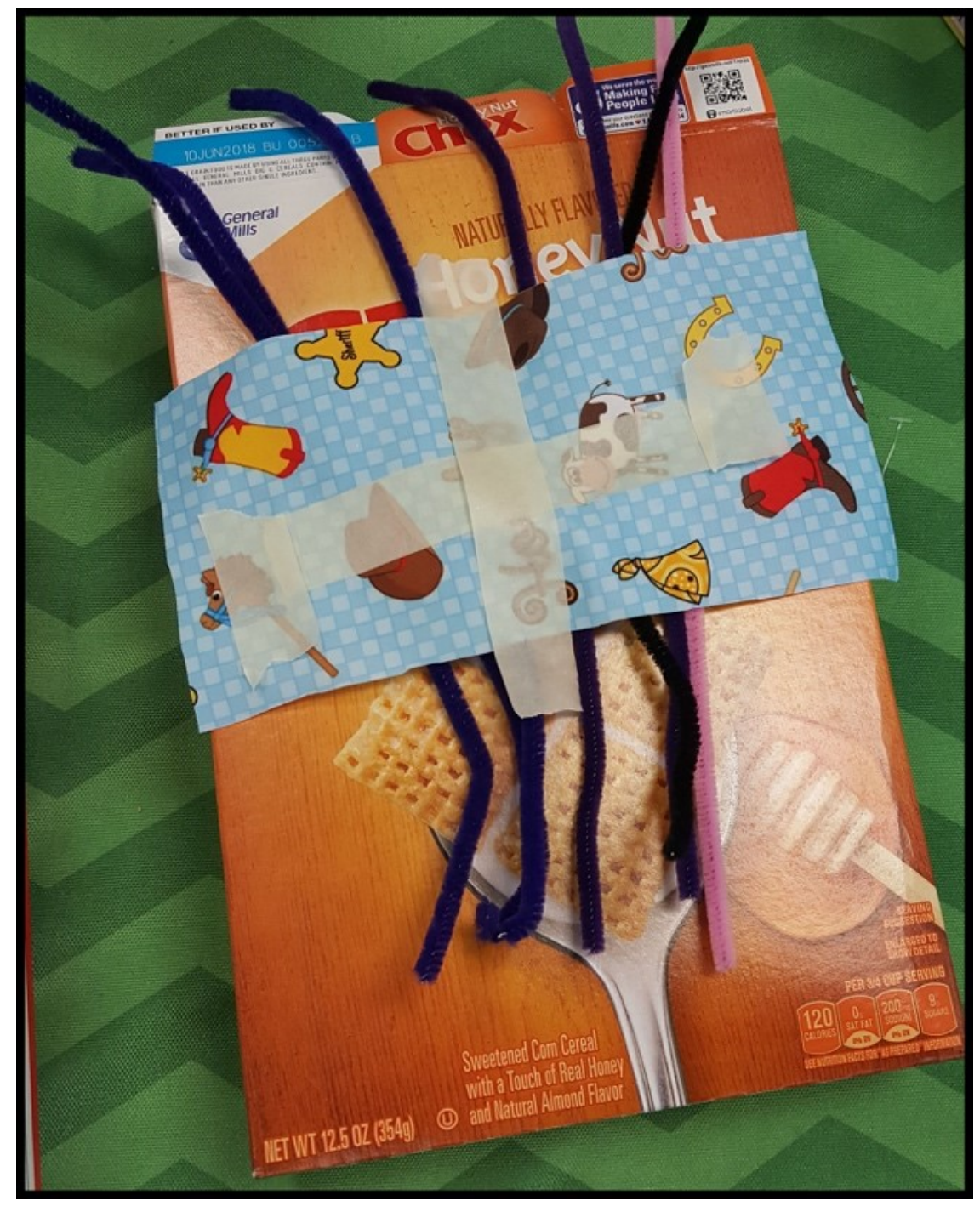

Figure 3. Example of a student prototype for Baa Baa Black Sheep. 


\section{Journal of Technology Education}

Vol. 30 No. 2, Spring 2019

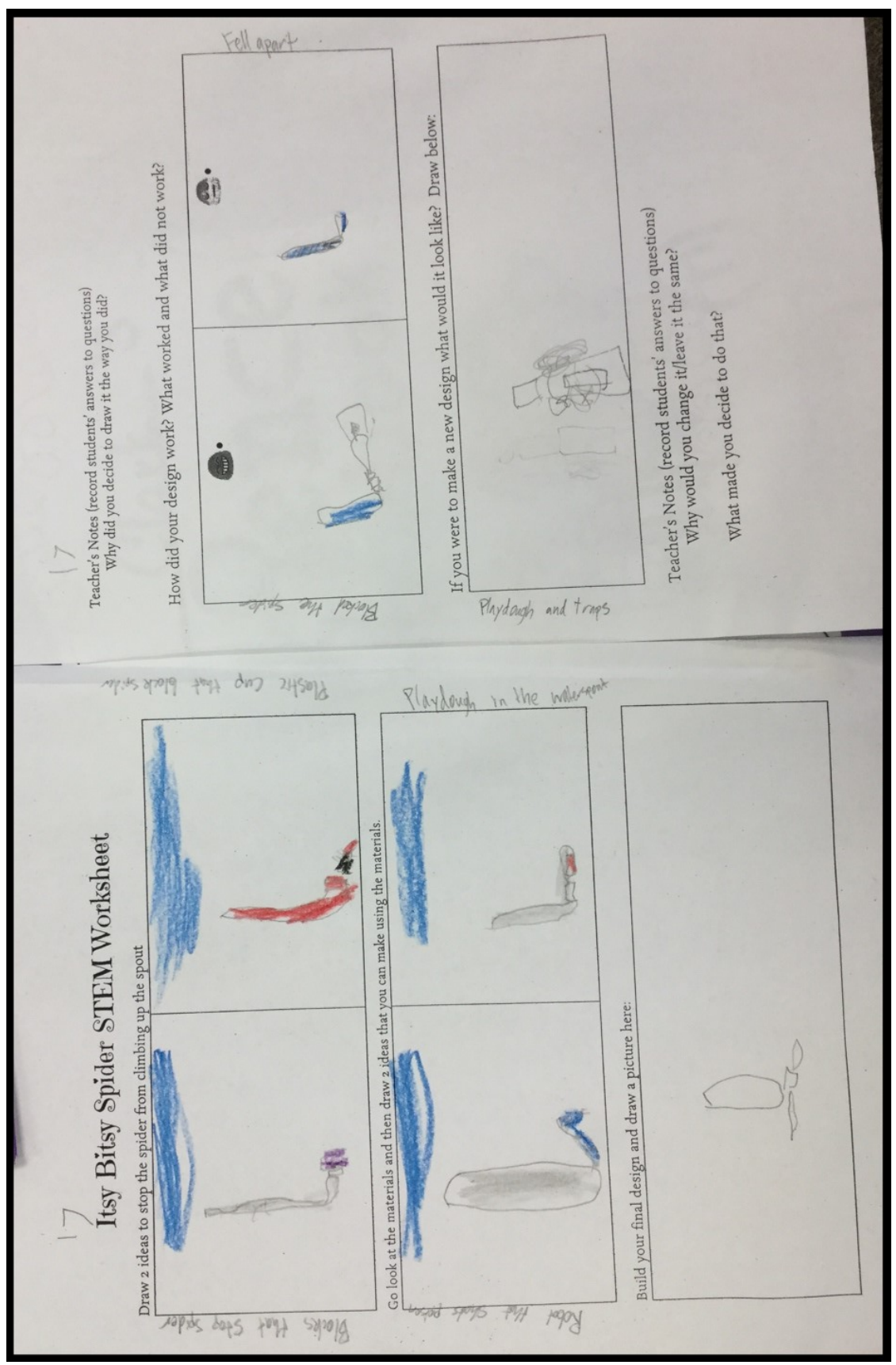

Figure 4. Example of completed portfolio (Itsy Bitsy Spider).

$-101-$ 
This process was repeated in each of the classrooms with the three tasks. Each of the iterations was conducted during class time and took approximately 1 hour to complete with the students. Following each design task, a picture was taken of the student portfolios and prototypes. The resulting data included 165 pictures of design portfolios and prototypes, collected from 55 participating students, from three open-ended design challenges centered on children's rhymes.

\section{Data Analysis}

All images of student prototypes and portfolios were collected and organized according to teacher and design task. After conducting a review of related literature and examining all 165 artifacts independently, the research team, which consisted of three licensed technology and engineering (TEE) teachers, met to discuss potential approaches used during the planning and evaluating stages of design. The researchers followed recommendations of Saldaña (2016) for the holistic coding of qualitative data. This process involved the initial meeting of researchers to identify potential approaches used by students, the generation of a list of potential codes, and then a coding process completed individually by the members of the research team. Following these initial steps, the codes were synthesized by the research team into the following categories:

1. Invention/Creation: developing a solution to the problem that emphasized something the student would create that did not already exist,

2. Application/Innovation: developing a solution to the problem that emphasized the use of an existing product or products to solve the problem, and

3. Method/Approach: developing a solution to the problem that emphasized how the students would solve the problem without explaining how the solution worked.

Following the solidification of the three categories identified above, members of the research team independently viewed each design portfolio, prototype image, and the accompanying descriptions and then assigned one of the initial codes to both the planning and evaluating stages of the design portfolios. After each section of each portfolio was assigned a code independently by two members of the research team, a second meeting was convened to discuss the results. Saldaña (2016) recommends reviewing the results, intercoder reliability, and revising and refining the codes until appropriate codes have been identified and reliability has been achieved. Following the first coding, a relatively low level of interrater reliability was achieved. Discussion amongst the research team led to a revision and identification of four possible codes with specific descriptions, which included: 
1. Black Box: students offer no explanation as to how the problem is solved but simply state that the problem will be solved,

2. Method/Approach: students don't specify what they will use to solve the problem but specify how they will solve the problem,

3. Application/Innovation: students will use an existing on-the-market product to solve the problem, and

4. Invention/Creation: students will make something novel to solve the problem.

Following the revision of the codes, members of the research team independently coded $100 \%$ of the planning and evaluating sections of all student design portfolios. Recognizing that many of the student solutions could potentially encapsulate multiple codes, it was determined that the coders would assign only one code at each stage and that the assigned code should represent the code that "best fit" the student's thinking — as determined by the coder. Coders followed a systematic process, questioning first if the solution was an Invention/Creation, then if the solution was an Application/Innovation, and so forth. The coders also noted problematic coding scenarios that could not be easily fit into one code- these problematic sections, of which there were a limited number, were discussed amongst the research team in follow-up meetings until a code was agreed upon. After this process, an interrater reliability was calculated to determine if there was agreement between the researchers assigned codes. There was moderate agreement between the researcher's judgements, $\kappa=.603$ (95\% CI, .503 to .703), $p<.0005$. Based on the agreement level obtained through the independent coding of all design portfolios, we determined to proceed with the data analysis related to our guiding research question.

\section{Findings}

The findings from this study were taken primarily from the qualitative analysis of pictures of student design portfolios and prototypes. All student drawings and responses were coded holistically by independent members of the research team, and after obtaining a sufficient interrater reliability for the assigned codes, all data were entered into statistical software (SPSS Version 23) for analysis.

The research question guiding our efforts was: What approaches do Kindergarten students use when making decisions in the process of resolving open-ended design tasks within integrated STEM learning contexts? Following the coding of responses, we determined to investigate this question by specifically analyzing the similarities and differences in approaches taken by students according to teacher, design task, and stage of design. In addition to related literature, these specific investigations were conducted based on observations made by the research team and the participating teachers during the design tasks. 
Teachers. A one-way ANOVA was conducted to investigate the potential influence of the teacher on the approaches that students used while designing at both the planning and evaluating stages of design. It was noted by the research team that students with different teachers (and thus different classrooms and teaching styles) appeared to gravitate towards different approaches - a decision potentially influenced by their classroom or teacher. An analysis of variance showed that the effect of teacher on approaches used by students in the planning stage was significant, $F(2,134)=3.86, p=.023$, but the effect of teacher on approaches used by students in the evaluation stage of design was not significant, $F(2,115)=1.94, p=.149$. These findings - that we recognize may be potentially influenced by other variables in addition to the teacher-may suggest that students approached problems differently at the planning stage based on the influence of their teachers. Further, these findings may suggest that different instructional emphases (i.e., teacher emphasis on criteria, creativity, or optimization) may influence the approaches utilized by students while designing.

All student responses, for both the planning and evaluating stages of design, were separated by teacher to further investigate how students approached design in each classroom. The total items coded in each of the identified categories for each teacher are included in Table 2.

Table 2

Student Approaches for Designing by Teacher for All Design Tasks

Design approach (count, percentage)

\begin{tabular}{ccccc}
\cline { 2 - 5 } & Black Box & $\begin{array}{c}\text { Method/ } \\
\text { Approach }\end{array}$ & $\begin{array}{c}\text { Application/ } \\
\text { Innovation }\end{array}$ & $\begin{array}{c}\text { Invention/ } \\
\text { Creation }\end{array}$ \\
\hline Teacher 1 & $22(42.3 \%)$ & $5(9.6 \%)$ & $6(11.5 \%)$ & $19(36.5 \%)$ \\
Teacher 2 & $9(20.5 \%)$ & $4(9.1 \%)$ & $15(34.1 \%)$ & $16(36.4 \%)$ \\
Teacher 3 & $0(0 \%)$ & $9(22 \%)$ & $21(51.2 \%)$ & $11(26.8 \%)$ \\
\hline
\end{tabular}

The students in Teacher 1's class predominantly approached their design task from a Black Box standpoint, stating that they would solve the problem but offering no indication as to how they would accomplish this, or from an Invention/Creation standpoint, proposing to build something new to solve the problem (see Figure 5 for an example). 


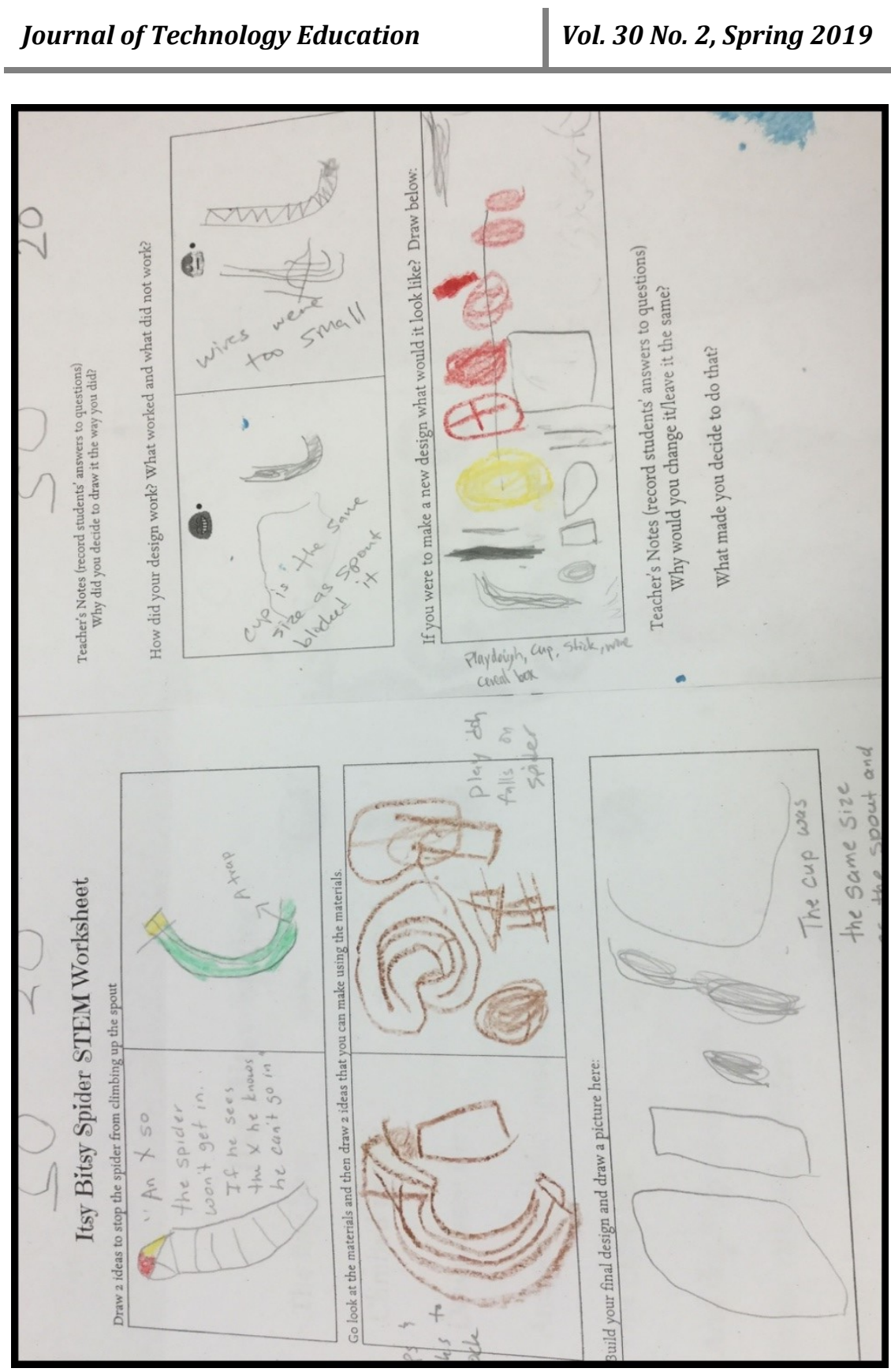

Figure 5. Example of a student portfolio in Teacher 1's class. The first box was coded as a Black Box approach, and the final box was coded as Invention/Creation. 
Alternatively, the students in Teacher 2's classroom approached the design tasks differently with an emphasis on either the Method or a Black Box approach. For example, one student explained that they planned to "make a box with three sticks and a headband around it all" for the planning portion, and in the evaluation portion, they changed their design to a box with rubber bands around it to separate the wool.

Finally, although many students in Teacher 3's classroom emphasized Application/Innovation or Black Box approaches, most of Teacher 3's students utilized an approach that revolved around a particular Method to solving the problem. This emphasis on an approach is exemplified by students describing methods of transporting the wool (e.g., using a truck).

Design Task. To investigate the potential effect of different design tasks on the approaches that students used while designing at both the planning and evaluating stages of design, a one-way ANOVA was conducted. The analysis of variance indicated that the effect of the design task on the approaches used by students in the planning and evaluation stages of design was significant. The effect of the task on design approaches used by students during planning was $F(2,134)=4.78, p=.010$, and the effect of task on the approaches used by students in the evaluation stage was $F(2,115)=3.58, p=.031$. These findings demonstrated a significant difference in the approaches to design by the students based on the assigned design task. Further analysis resulted in the frequencies of each approach used by students (see Table 3).

Table 3

Student Approaches for Designing by Task

Design approach (count, percentage)

\begin{tabular}{lcccc}
\cline { 2 - 4 } & Black Box & $\begin{array}{c}\text { Method/ } \\
\text { Approach }\end{array}$ & $\begin{array}{c}\text { Application/ } \\
\text { Innovation }\end{array}$ & $\begin{array}{c}\text { Invention/ } \\
\text { Creation }\end{array}$ \\
\hline $\begin{array}{l}\text { Task 1: } \\
\text { Itsy Bitsy Spider }\end{array}$ & $8(15.7 \%)$ & $9(17.6 \%)$ & $6(11.8 \%)$ & $28(54.9 \%)$ \\
$\begin{array}{l}\text { Task 2: } \\
\text { Baa Baa Black Sheep }\end{array}$ & $18(36 \%)$ & $3(6 \%)$ & $21(42 \%)$ & $8(16 \%)$ \\
$\begin{array}{l}\text { Task 3: } \\
\text { Little Boy Blue }\end{array}$ & $5(9.1 \%)$ & $9(16.4 \%)$ & $31(56.4 \%)$ & $10(18.2 \%)$ \\
\hline
\end{tabular}

The Itsy Bitsy Spider design challenge involved students designing and prototyping a solution to keep the spider from climbing the water spout while still allowing rainwater to escape. This task was primarily approached by students from an Invention/Creation standpoint. Students offered a variety of solutions that they would create including things such as building a wall, making an object with spikes by the spout, and making a no entry sign for the spout (see 
Figure 6).

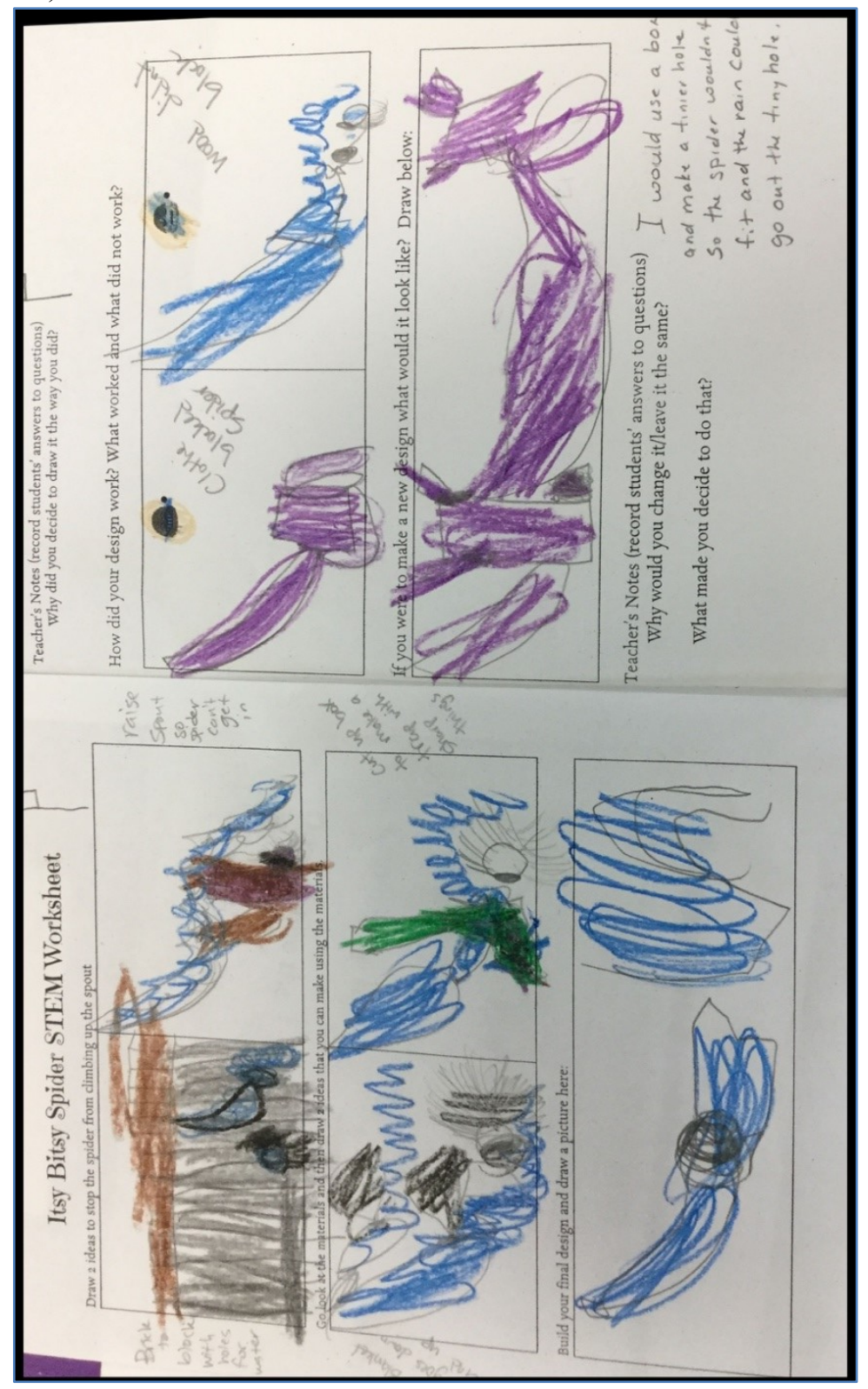

Figure 6. Example of a student portfolio during the Itsy Bitsy Spider task. Both boxes were coded as Invention/Creation. 
For the second task, students were tasked with designing and prototyping something to separate sheep's wool. Although some students (36\%) took a Black Box approach to solving this problem, offering solutions such as using flowers and boxes, putting them in something to be delivered, and using something made of metal, this challenge was predominantly approached from an Application/Innovation approach (42\%) with students offering ideas such as: using a stick for separation, cutting the wool with scissors, and using a knife.

In the third task, the students were tasked with designing and prototyping something to help wake Little Boy Blue so that the cows and sheep would not escape the pasture. Overwhelmingly, the students took an Application/Innovation approach (56.4\%) and emphasized the application of existing products to wake Little Boy Blue (e.g., alarm clock or bell).

Stage of Design. Finally, to investigate if design approaches used by primary school children were different at various stages of design (e.g., planning and evaluating), a chi-square goodness of fit was computed to compare the approaches of students during these stages of design. The results indicated a significant interaction between design approach and stage of designing at both the planning $\left(\chi^{2}(3)=13.80, p<.05\right)$ and evaluating $\left(\chi^{2}(3)=29.66, p<.05\right)$ stages of design. Students were most likely to use either an Application/Innovation-based approach (30.7\%) or an Invention/Creation approach (33.6\%) at the planning stage. For the evaluating stage, students were most likely to use an Invention/Creation approach to design (44.9\%).

\section{Discussion}

The findings, related to the analysis of the student work and the potential relationships with several other factors, presented several interesting findings. These will be discussed in turn with potential implications.

Teacher Differences. Previous research suggests that the influence of teachers on students' achievement, attitudes, and experiences is significant (Darling-Hammond, 2000) and that students design experiences can differ based on their teacher (Bartholomew et al., 2017). Although the approaches students used in the evaluating stage of design were not significantly different for each teacher, the approaches students used during the planning stage of design were significantly different. Teachers may be able to significantly influence their students regarding best practices, effective approaches, and positive planning for designing. Identifying the best approaches and training teachers on how to assist their students in incorporating these may result in improved design approaches for their students. Relatedly, we investigated the impact of school on the differences in how students approach design problems but found no significant difference at either the planning or evaluating stages of design based on the students from different participating schools. 
Interestingly, the variance in student approaches to designing, based on teacher differences, was not significant at the evaluating stage of design. This finding suggests that, although student initial approaches to design may be significantly influenced by their teachers and classroom experiences, student approaches to designing at the evaluating stage may be influenced by other factors. Of note, the researchers noticed several common "mistakes," "misnomers," and "design flaws" across all classrooms--for example, many students designed a way to keep the spider from going up the water spout but failed to account for the constraint of allowing the water to flow freely through the spout. It is possible that these common "mistakes," across all participating teachers, contributed to a less significant impact of teacher on how students approached design at the evaluating stage of the project. As students fell into similar struggles and challenges, their evaluating responses may have become more "standardized" and less significantly influenced by the differences in their teachers and classrooms. Moreover, it is possible that this finding may be a result of differences in instruction provided to students related to understanding criteria and constraints or the refining and optimization of designs.

Design Task Differences. Three design tasks, all revolving around problems included in children's rhymes, were used with the Kindergarten students in this study (see Table 2). The first problem asked the students to design and prototype a way to keep the Itsy Bitsy Spider from climbing the water spout with the constraint of the design needing to allow the rainwater to flow freely through the spout. For this challenge, students primarily used an approach that revolved around them Inventing/Creating something new to solve the problem. This was unique because the other two challenges-Baa Baa Black Sheep, which asked the students to devise a way to separate wool, and Little Boy Blue, which asked students to design a way to wake Little Boy Blue if the cows or sheep went to the meadow or corn - both involved student approaches to design that emphasized the Method/Approach rather than Inventing/Creating.

These differences may be simply a function of the differences in the problem. For example, in the Itsy Bitsy Spider problem, the students had to block a living organism from a certain area; in the second, the students needed to separate an inanimate object; and in the third, the students needed to wake a sleeping individual. Alternatively, it is worth noting that the Itsy Bitsy Spider was the first experience introduced to the students; therefore, it is possible that the differences in approaches were simply a result of the timing, experience, and exposure of the students to the design problems - with students initially approaching problems from an Invention/Creation standpoint and moving to a more Methods-based approach as they gained more experience.

However, the different design approaches revealed in this study may also demonstrate variance in student results for different tasks as a result of the criteria and constraints presented in the given problem scenario. In light of these findings, we recommend that further investigations seek a better understanding 
of which approach (or approaches) may be best suited for different types of situations rather than which approach (or approaches) are best overall.

Design Stage Differences. The students approached their designing with significantly different approaches at both the planning and evaluating stages of design. At the planning stage the students emphasized both Application/Innovation and Invention/Creation approaches, but the most significant difference was found at the evaluating stage where students primarily used an Invention/Creation approach to design. The significant differences in how students approached the design tasks at each stage may be related to a variety of factors (including many already discussed). We theorize that students emphasized an Invention/Creation approach to design during the evaluation stage of design primarily because they were asked to identify how they would solve the problem if they started over-this question may lead to an emphasis on what they would make or create. However, the students' emphasis on an Invention/Creation approach may be a result of other factors such as their experience - which sometimes included failure, struggles, and other learning experiences - during the design challenges or something else altogether.

Stage of Design. Finally, to investigate if design approaches used by primary school children were different at various stages of design, a chi-square goodness of fit was computed to compare the approaches of students during the planning and evaluating stages of design. The results indicated a significant interaction between approach to designing and stage of designing at both the planning and evaluating stages of design. Students were most likely to use either an Application/Innovation approach (30.7\%) or Invention/Creation approach $(33.6 \%)$ at the planning stage. For the evaluating stage, students were most likely to use an Invention/Creation approach (44.9\%).

\section{Conclusion}

This study set out to explore approaches used by Kindergartners in solving open-ended design problems through a qualitative analysis of student design portfolios completed during three consecutive open-ended design challenges involving children's rhymes. Our research involved holistic coding (Saldaña, 2016) of student responses during the planning and evaluating stages of design (Fleer, 2000) with four approaches emerging from analysis of the data, including: (1) a Black Box approach wherein the students offered no explanation as to how the problem would be solved, (2) a Method/Approach in which a student focused on a particular method for solving the problem, (3) an Application/Innovation approach that focused on the application of an existing product, and (4) an Invention/Creation approach that focused on creating a new product to solve the problem. The analysis of data included investigating the impact of teacher, design task, and stage of design on the approach (or approaches) used by students during each design task and across all three design challenges. 
Despite a teacher script, prescribed design portfolios and problems, and comparability in classrooms, teachers, and students, the analysis revealed a significant difference in how the students approached the design problems based on their different teachers, the different design tasks, and the stage of design in which they were engaged (e.g., planning or evaluating). These findings raise important considerations related to the introduction of design tasks with young students. Namely, those wishing to introduce and use these problems in their classrooms should recognize the potential for students to approach these problems in significantly different ways.

Further, students may attempt to design problems through a variety of approaches that may change from problem to problem, classroom to classroom, and even during the duration of one design problem. We contend that future efforts towards identifying best practices or approaches to design should consider multiple best approaches that may vary based on problem, task, teacher, student, or stage of design. Perhaps there are no best approaches to design that can be broadly applied but a variety of potentially-useful approaches that are dependent on multiple variables related to the designer, task, instructor, and design timeline. Future efforts, with larger variance in students, teachers, or design problems, may shed additional light on these differences and expand our understanding of how primary school children approach these open-ended design challenges.

\section{References}

Arter, J. A., \& Spandel, V. (1992). Using portfolios of student work in instruction and assessment. Educational Measurement: Issues and Practice, 11(1), 36-44. doi:10.1111/j.1745-3992.1992.tb00230.x

Bartholomew, S. R., Reeve, E., Veon, R., Goodridge, W., Lee, V., \& Nadelson, L. (2017). Relationships between access to mobile devices, self-directed learning, and achievement. Journal of Technology Education, 29(1), 2-24. doi:10.21061/jte.v29i1.a.1

Bartholomew, S. R., \& Strimel, G. J. (2018). Factors influencing student success on open-ended design problems. International Journal of Technology and Design Education, 28(3), 753-770. doi:10.1007/s10798-017-9415-2

Bencze, J. L. (2010). Promoting student-led science and technology projects in elementary teacher education: Entry into core pedagogical practices through technological design. International Journal of Technology and Design Education, 20(1), 43-62. doi:10.1007/s10798-008-9063-7

Brophy, S., Klein, S., Portsmore, M., \& Rogers, C. (2008). Advancing engineering education in P-12 classrooms. Journal of Engineering Education, 97(3), 369-387. doi:10.1002/j.2168-9830.2008.tb00985.x

Cohen, D. (2002). How the child's mind develops. London, England: Routledge. Crossland, J. (2015). Is Piaget wrong? Primary Science, 137, 30-32. 
Darling-Hammond, L. (2000). Teacher quality and student achievement: A review of state policy evidence. Education Policy Analysis Archives, 8, Article 1. doi:10.14507/epaa.v8n1.2000

De Fina, A. A. (1992). Portfolio assessment: Getting started. New York, NY: Scholastic.

Diefes-Dux, H. A., Moore, T., Zawojewski, J., Imbrie, P. K., \& Follman, D. (2004). A framework for posing open-ended engineering problems: Modeleliciting activities. In 34th ASEE/IEEE Frontiers in Education Conference (pp. F1A-3-F1A-8). Piscataway, NJ: Institute of Electrical and Electronics Engineers. Retrieved from http://archive.fieconference.org/fie2004/papers/1719.pdf

Dixon, R. (2016, November). Is engineering design being effectively used in the engineering and technology education classroom? Paper presented at the 103rd Annual Mississippi Valley Technology Teacher Education Conference, Rosemont, IL.

Epstein, D., \& Miller, R. T. (2011). Slow off the mark: Elementary school teachers and the crisis in science, technology, engineering, and math education. Washington, DC: Center for American Progress. Retrieved from https://www.americanprogress.org/issues/education-k12/reports/2011/05/04/9680/slow-off-the-mark/

Fleer, M. (2000). Working technologically: Investigations into how young children design and make during technology education. International Journal of Technology and Design Education, 10(1), 43-59. doi:10.1023/A:1008923410441

Goldstone, R. L., \& Sakamoto, Y. (2003). The transfer of abstract principles governing complex adaptive systems. Cognitive psychology, 46(4), 414466. doi:10.1016/S0010-0285(02)00519-4

Griffin, P., \& Care, E. (Eds.). (2015). Assessment and teaching of 21 st century skills: Methods and approach. Dordrecht, the Netherlands: Springer. doi:10.1007/978-94-017-9395-7

Grubbs, M. E., Strimel, G. J., \& Kim, E. (2018). Examining design cognition coding schemes for P-12 engineering/technology education. International Journal of Technology and Design Education, 28(4), 899-920. doi:10.1007/s10798-017-9427-y

Hall, B. W., \& Hewitt-Gervais, C. M. (2000). The application of student portfolios in primary-intermediate and self-contained-multiage team classroom environments: Implications for instruction, learning, and assessment. Applied Measurement in Education, 13(2), 209-228. doi:10.1207/S15324818AME1302_5

Honey, M., \& Kanter, D. E. (Eds.). (2013). Design, make, play: Growing the next generation of STEM innovators. New York, NY: Routledge. doi:10.4324/9780203108352 
Honey, M., Pearson, G., \& Schweingruber, H. (Eds.). (2014). STEM integration in K-12 education: Status, prospects, and an agenda for research. Washington, DC: National Academies Press. doi:10.17226/18612

International Technology Education Association. (2007). Standards for technological literacy: Content for the study of technology (3rd ed.). Reston, VA: Author.

Jacobs, G. M. (2001). Providing the scaffold: A model for early childhood/primary teacher preparation. Early Childhood Education Journal, 29(2), 125-130. doi:10.1023/A:1012581113983

Johnson, R. S., Mims-Cox, J. S., \& Doyle-Nichols, A. (2010). Developing portfolios in education: A guide to reflection, inquiry, and assessment (2nd ed.). Thousand Oaks, CA: Sage.

Jonassen, D. H. (2008). Instructional design as design problem solving: An iterative process. Educational Technology, 48(3), 21-26.

Katehi, L., Pearson, G., \& Feder, M. (Eds.). (2009). Engineering in K-12 education: Understanding the status and improving the prospects. Washington, DC: National Academies Press. doi:10.17226/12635

Kelley, T., \& Sung, E. (2017). Examining elementary school students' transfer of learning through engineering design using think-aloud protocol analysis. Journal of Technology Education, 28(2), 83-108. doi:10.21061/jte.v28i2.a.5

Kelley, T. R., Capobianco, B. M., \& Kaluf, K. J. (2015). Concurrent think-aloud protocols to assess elementary design students. International Journal of Technology and Design Education, 25(4), 521-540. doi:10.1007/s10798014-9291-y

Koch, J., \& Burghardt, M. D. (2002). Design technology in the elementary school-A study of teacher action research. Journal of Technology Education, 13(2), 21-33. doi:10.21061/jte.v13i2.a.2

Cunningham, C., \& Lachapelle, C. (2007). Engineering is elementary: Children's changing understandings of science and engineering. In $A S E E$ 2007 Annual Conference \& Exposition (pp. 12.640.1-12.640.33). Washington, DC: American Society for Engineering Education. Retrieved from https://peer.asee.org/1470

León, J., Núñez, J. L., \& Liew, J. (2015). Self-determination and STEM education: Effects of autonomy, motivation, and self-regulated learning on high school math achievement. Learning and Individual Differences, 43, 156-163. doi:10.1016/j.lindif.2015.08.017

Marra, R. M., Rodgers, K. A., Shen, D., \& Bogue, B. (2009). Women engineering students and self-efficacy: A multi-year, multi-institution study of women engineering student self-efficacy. Journal of Engineering Education, 98(1), 27-38. doi:10.1002/j.2168-9830.2009.tb01003.x 
Morrison, J. S. (2006). Attributes of STEM education: The student, the academy, the classroom. TIES STEM education monograph series. Baltimore, MD: Teaching Institute for Essential Science.

National Research Council. (2011). Successful K-12 STEM education: Identifying effective approaches in science, technology, engineering, and mathematics. Washington, DC: National Academies Press. doi:10.17226/13158

National Research Council. (2012). A framework for K-12 science education: Practices, crosscutting concepts, and core ideas. Washington, DC: National Academies Press. doi:10.17226/13165

Nicolaidou, I. (2013). E-portfolios supporting primary students' writing performance and peer feedback. Computers \& Education, 68, 404-415. doi:10.1016/j.compedu.2013.06.004

Pringle, A., \& Sowden, P. T. (2017). Unearthing the creative thinking process: Fresh insights from a think-aloud study of garden design. Psychology of Aesthetics, Creativity, and the Arts, 11(3), 344-358. doi:10.1037/aca0000144

Resnick, M. (1998). Technologies for lifelong Kindergarten. Educational Technology Research and Development, 46(4), 43-55. doi:10.1007/BF02299672

Rich, P J., Jones, B. L., Belikov, O., Yoshikawa, E., \& Perkins, M. (2017). Computing and engineering in elementary school: The effect of year long training on elementary teacher self-efficacy and beliefs about teaching computing and engineering. International Journal of Computer Science Education in Schools, 1(1), 1-20. doi:10.21585/ijcses.v1i1.6

Saldaña, J. (2016). The coding manual for qualitative researchers (3rd ed.). Thousand Oaks, CA: Sage.

Savery, J. R. (2015). Overview of problem-based learning: Definitions and distinctions. In A. Walker, H. Leary, C. Hmelo-Silver, \& P. A. Ertmer (Eds.), Essential readings in problem-based learning: Exploring and extending the legacy of Howard S. Barrows (pp. 5-15). West Lafayette, IN: Purdue University Press.

Schallhart, E., \& Wieden-Bischof, D. (2010). Working with e-portfolios in Kindergarten institutions. In N. A. Buzzetto-More (Ed.), The e-portfolio paradigm: Informing, educating, assessing, and managing with e-portfolios (pp. 141-159). Santa Rosa, CA: Informing Science Press.

Sloutsky, V. M., Kaminski, J. A., \& Heckler, A. F. (2005). The advantage of simple symbols for learning and transfer. Psychonomic Bulletin \& Review, 12(3), 508-513. doi:10.3758/BF03193796

Stohlmann, M., Moore, T. J., \& Roehrig, G. H. (2012). Considerations for teaching integrated STEM education. Journal of Pre-College Engineering Education Research, 2(1), 28-34. doi:10.5703/1288284314653 
Strimel, G. J., Bartholomew, S. R., Kim, E., \& Zhang, L. (2018). An investigation of engineering design cognition and achievement in primary school. Journal of STEM Education Research, 1(1-2), 173-201. doi:10.1007/s41979-018-0008-0

Strimel, G. J., Kim, E., Bartholomew, S. R., \& Cantu, D. V. (2018). Examining engineering design cognition with respect to student experience and performance. International Journal of Engineering Education, 34(6), 19101929.

Strimel, G. J., \& Grubbs, M. E. (2017). A critical examination of engineering design processes and procedures. Paper presented at the 2017 Pupils Attitudes Towards Technology Conference, Philadelphia, PA. Retrieved from https://www.iteea.org/File.aspx?id=115739\&v=21dfd7a

Sutherland, P. (1992). Cognitive development today: Piaget and his critics. London, England: Chapman.

Swift, T. M., \& Watkins, S. E. (2004). An engineering primer for outreach to K4 education. Journal of STEM Education: Innovations and Research, 5(34), 67-76. Retrieved from https://www.jstem.org/jstem/index.php/JSTEM/article/view/1131/986

Tyler-Wood, T., Knezek, G., \& Christensen, R. (2010). Instruments for assessing interest in STEM content and careers. Journal of Technology and Teacher Education, 18(2), 345-368.

Weiten, W. (1992). Psychology: Themes and variations (2nd ed.). Belmont, CA: Brooks/Cole.

Yoshikawa, E., \& Bartholomew, S. R. (2017). STEM children's rhymes: Itsy Bitsy Spider. Children's Technology and Engineering, 22(1), 25-29.

Yoshikawa, E., \& Bartholomew, S. R. (2018a). STEM children's rhymes: STEM Baa Baa Black Sheep. Children's Technology and Engineering, 22(3), 22-25.

Yoshikawa, E., \& Bartholomew, S. R. (2018b). STEM children's rhymes: STEM Little Boy Blue. Children's Technology and Engineering, 23(1), 2225.

Zubizarreta, J. (2009). The learning portfolio: Reflective practice for improving student learning (2nd ed.). San Francisco, CA: Wiley.

\footnotetext{
About the Authors

Scott R. Bartholomew (sbartho@purdue.edu) is Assistant Professor of Engineering Technology Teacher Education at Purdue University.

Cameron Moon (moon108@purdue.edu) is a graduate research assistant in Engineering Technology Teacher Education at Purdue University.

Emily Yoshikawa Ruesch (emruesch@wsd.net) is a high school technology \& engineering teacher in Weber School District, Weber, Utah.

Greg J. Strimel (gstrimel@purdue.edu) is Assistant Professor of Engineering Technology Teacher Education at Purdue University.
} 